Check for updates

Cite this: RSC Adv., 2019, 9, 28576

\title{
Microwave-assisted iodine-catalyzed oxidative coupling of dibenzyl(difurfuryl)disulfides with amines: a rapid and efficient protocol for thioamides $\dagger$
}

\author{
Jinyang Chen, (D) ${ }^{a}$ Lan Mei, ${ }^{a}$ Jialing Liu, ${ }^{a}$ Chuntao Zhong, ${ }^{a}$ Binfang Yuan (D) *a \\ and Qiang Li (D) ${ }^{b}$
}

Received 31st July 2019

Accepted 3rd September 2019

An efficient protocol for synthesis of thioamides was developed via the microwave-assisted iodinecatalyzed oxidative coupling of dibenzyl(difurfuryl)disulfides with amines. This process is scalable and tolerates a wide spectrum of amines to deliver the corresponding products in moderate to excellent yields in 10 minutes, providing a cheap and rapid approach to thioamides.

rsc.li/rsc-advances

of amines. Thiols can also be used as sulfur reagent for

Thioamides have become an attractive synthetic goal in organic chemistry, ${ }^{1}$ because thioamide skeletons are widely present in drugs and natural products, ${ }^{2}$ such as cycasthioamide, ${ }^{3}$ 6-thioyuanine, ${ }^{4}$ 2-thiocytidine ${ }^{5}$ and closthioamide ${ }^{2 a}$ (Scheme 1), and their application as useful precursors and versatile building blocks for construction of a range of heterocyclic compounds has also been studied. ${ }^{1 a, 6}$ In addition, thioamides also can be used as a synthetic isostere for amides in peptide backbones, ${ }^{7}$ and their application as directing groups has also been reported. ${ }^{8,1 c}$ Furthermore, the application of thioamides in developing novel a fluorophore/quencher pair for monitoring the unfolding of a small protein was also explored. ${ }^{9}$

Because of their wide application, efforts are devoted toward their generation. ${ }^{10}$ The Willgerodt-Kindler reaction is a wellknown method for construction of thioamides by using aldehydes and secondary amines as starting materials. ${ }^{11}$ However, this thioamidation always suffers from the problems of low conversions and harsh conditions. Though, modified variations in Willgerodt-Kindler reaction were also reported, ${ }^{1 a, 12}$ the use of excessive amounts of elemental sulphur makes it a less economical method. Lawesson's reagent was also used as common sulfur reagent for synthesis of thioamides, ${ }^{13}$ however, this reaction was also occur under harsh conditions. Another thioamidation, where elemental sulfur was used as sulfur reagent, was also reported by Savateev's groups via a photoinitiated reaction (Scheme 2a). ${ }^{11 a}$ However, this transformation was only suitable for special thioamides with the same structure

${ }^{a}$ College of Chemistry and Chemical Engineering, Yangtze Normal University, Fuling, Chongqing, 408000, P. R. China. E-mail: 6781022@163.com

${ }^{b}$ Institution of Functional Organic Molecules and Materials, School of Chemistry and Chemical Engineering, Liaocheng University, No. 1, Hunan Street, Liaocheng, Shandong, 252059, P. R. China

$\dagger$ Electronic supplementary information (ESI) available. See DOI: $10.1039 / \mathrm{c} 9 \mathrm{ra} 05939 \mathrm{c}$ construction of thioamides, ${ }^{13 b, c}$ but its pungent smell makes this reaction difficult to carry out (Scheme 2b). Recently, Nguyen's group described a novel process to thioamides by using sulfur as catalyst. ${ }^{14}$ This method was suitable for a large range of amines for giving the corresponding products in good to excellent yields at $80^{\circ} \mathrm{C}$ for a long time of $16 \mathrm{~h}$.

Other methods for thioamides were also reported, ${ }^{15}$ but challenges still exist in developing more convenient and efficient ways to these important scaffolds. In our previous work, thioamides were synthesized via the iodine-promoted thioamidation of several of amines. ${ }^{16}$ However, this reaction must be performed under high temperature, for a long time $\left(100^{\circ} \mathrm{C}\right.$, $8.0 \mathrm{~h}$ ), and 0.5 equiv. of $\mathrm{I}_{2}$ must to be used to promote the thioamidation effectively (Scheme 2c).

As one of the efficient and clean procedures in modern synthetic organic chemistry, microwave-assisted organic synthesis (MAOS) has aroused wide interest among scientists, which are suited to the increased demands in industry with the advantages of short reaction times and expanded reaction range. ${ }^{17}$ Herein, we reported an efficient method for synthesis of thioamides via the

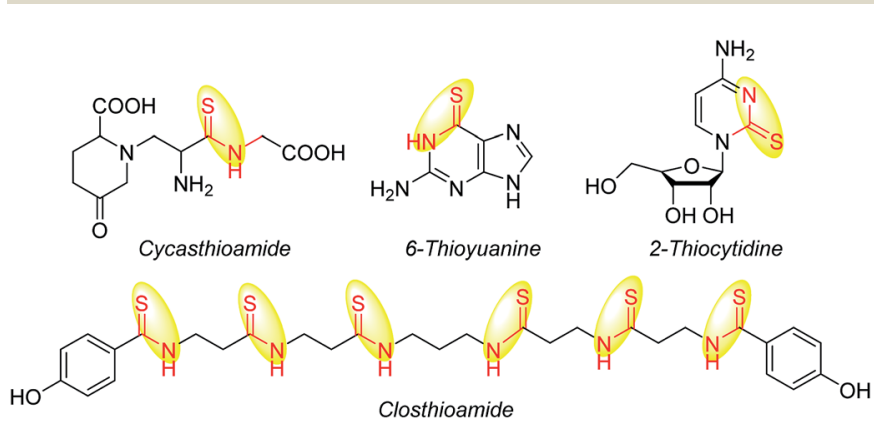

Scheme 1 Structures of natural products bearing thiocarbonyl group. 


\section{Previous works}

(a) Elemental sulfur as sulfur reagent

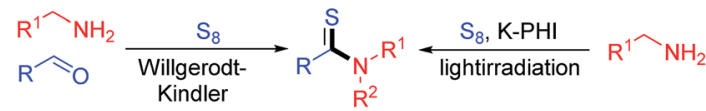

(b) Thiols as sulfur reagent

$$
\mathrm{R}-\mathrm{SH}+\mathrm{R}^{\prime}-\mathrm{RH}_{\mathrm{R}}^{\prime} \frac{\mathrm{Cu}(\mathrm{II}), \mathrm{TBD}(1.0 \text { equiv. })}{100^{\circ} \mathrm{C}, 18 \mathrm{~h}, \mathrm{O}_{2}(1 \mathrm{~atm})} \mathrm{R}_{\substack{\mathrm{N}^{\prime} \\ \mathrm{R}^{\prime}}}^{\mathrm{C}^{\prime}}
$$

(c) Disulfide as sulfur reagent

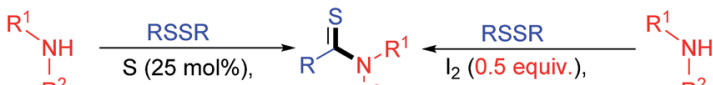

$$
\begin{aligned}
& \mathrm{R}^{2} \text { DMSO, } 800^{\circ} \mathrm{C}, 16 \mathrm{~h} \quad \mathrm{R}^{2} \quad \mathrm{DMSO}^{\circ} 100^{\circ} \mathrm{C}, 8 \mathrm{~h} \quad \mathrm{R}^{2}
\end{aligned}
$$

This work

(d) Microwave-assisted iodine-catalyzed coupling reaction

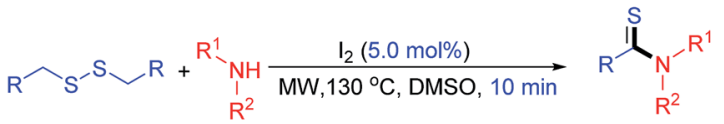

Rapid thioamidation: $10 \mathrm{~min}$ Wide functional group tollerence Good to excellent yields: up to $92 \%$

Scheme 2 General methods for synthesis of thioamides.

microwave-assisted iodine-catalyzed oxidative coupling of dibenzyl(furan-2-ylmethyl) disulfides with amines (Scheme 2d).

We initiated our studies with the reaction of dibenzyldisulfide (1a) with $N$-methylpiperazine (2a) catalyzed by $10 \mathrm{~mol} \%$ of $\mathrm{I}_{2}$ in DMSO under microwave radiation $\left(100{ }^{\circ} \mathrm{C}\right)$ for 10 minutes, and the desired product (3a) was obtained in the yield of $36 \%$ (Table 1, entry 1). The reaction temperature affected the reaction obviously, and highest yield was obtained when the temperature was increased to $130{ }^{\circ} \mathrm{C}$ for 10 minutes (Table 1 , entry 4). But no increase in yield was observed when the temperature was increased to $140{ }^{\circ} \mathrm{C}$ (Table 1 , entry 5) and the reaction time to 15 minutes (Table 1 , entry 8 ). Next, a series of solvents (such as DMSO, DMF, 1,4-dioxane, THF, $\mathrm{CH}_{3} \mathrm{CN}$, HOAc, chlorobenzene and toluene, or solvent-free) were also examined to promote the reaction (Table 1, entries 7-14), and results showed that DMSO is the best solvent, affording the desired product (3a) in the yield of $88 \%$ in 10 minutes (Table 1 , entry 4). Then we explored the influence of the catalyst on the thioamidation, and results showed that the amount of $5.0 \mathrm{~mol} \%$ of $\mathrm{I}_{2}$ was enough to promote the reaction effectively (88\%, Table 1, entry 15). The yield of desired product decreased to $73 \%$ and $78 \%$ respectively, even extending the reaction time to 15 minutes, when $3.0 \mathrm{~mol} \%$ of $\mathrm{I}_{2}$ was used. In addition, no increase in yield was observed, when the ratio of reactants $(2 \mathbf{a} /$ 1a) was increased to 3.0 (Table 1 , entry 18 ). Only $18 \%$ of desired product was obtained, when the reaction was performed in the presence of $5.0 \mathrm{~mol} \%$ of $\mathrm{I}_{2}$ in DMSO at $130{ }^{\circ} \mathrm{C}$ for 10 minutes without microwave irradiation (Table 1, entry 18). After extensive screening, we were glad to find that the reaction of dibenzyldisulfide (1a) with $N$-methylpiperazine (2a) in DMSO catalyzed by $5.0 \mathrm{~mol} \%$ of $\mathrm{I}_{2}$ and assisted by microwave radiation provided the desired product (3a) with an excellent yield of $88 \%$ within $10 \mathrm{~min}$ (Table 1, entry 15).

With the optimal conditions in hand, the scope of the amines and disulfides were investigated, and results were

\begin{tabular}{|c|c|c|c|c|c|}
\hline Entry & $\mathrm{I}_{2}(\mathrm{~mol} \%)$ & Solvent & Temp. $\left({ }^{\circ} \mathrm{C}\right)$ & Time (min) & Yield $^{b}(\%)$ \\
\hline 1 & $\mathrm{I}_{2}(10 \mathrm{~mol} \%)$ & DMSO & 100 & 10 & $36 \%$ \\
\hline 2 & $\mathrm{I}_{2}(10 \mathrm{~mol} \%)$ & DMSO & 110 & 10 & $48 \%$ \\
\hline 4 & $\mathrm{I}_{2}(10 \mathrm{~mol} \%)$ & DMSO & 130 & 10 & $88 \%$ \\
\hline 5 & $\mathrm{I}_{2}(10 \mathrm{~mol} \%)$ & DMSO & 140 & 10 & $88 \%$ \\
\hline 6 & $\mathrm{I}_{2}(10 \mathrm{~mol} \%)$ & DMSO & 130 & 15 & $88 \%$ \\
\hline 9 & $\mathrm{I}_{2}(10 \mathrm{~mol} \%)$ & THF & 130 & 10 & $65 \%$ \\
\hline 10 & $\mathrm{I}_{2}(10 \mathrm{~mol} \%)$ & $\mathrm{CH}_{3} \mathrm{CN}$ & 130 & 10 & $70 \%$ \\
\hline 11 & $\mathrm{I}_{2}(10 \mathrm{~mol} \%)$ & HOAc & 130 & 10 & $62 \%$ \\
\hline 12 & $\mathrm{I}_{2}(10 \mathrm{~mol} \%)$ & Chlorobenzene & 130 & 10 & $74 \%$ \\
\hline 13 & $\mathrm{I}_{2}(10 \mathrm{~mol} \%)$ & Toluene & 130 & 10 & $63 \%$ \\
\hline 14 & $\mathrm{I}_{2}(10 \mathrm{~mol} \%)$ & Solvent-free & 130 & 10 & $21 \%$ \\
\hline $19^{e}$ & $\mathrm{I}_{2}(5 \mathrm{~mol} \%)$ & DMSO & 130 & 10 & $18 \%$ \\
\hline
\end{tabular}
summarized in Table 2. As shown in Table 2, we can see that

Table 1 Optimization of the reaction conditions ${ }^{a}$

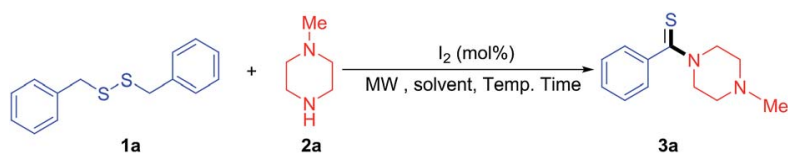

${ }^{a}$ Reaction conditions: dibenzyldisulfide 1a $(0.2 \mathrm{mmol}), N$-methylpiperazine $2 \mathrm{2a}(0.4 \mathrm{mmol}), \mathrm{I}_{2}$, solvent $(2.0 \mathrm{~mL}) .{ }^{b} \mathrm{GC}$ yields based on dibenzyldisulfide 1a. ${ }^{c}$ Isolated yields based on dibenzyldisulfide 1a. ${ }^{d} 0.6 \mathrm{mmol}$ of $N$-methylpiperazine 2 a was used. ${ }^{e}$ Without microwave radiation. 
Table 2 Microwave-assisted iodine-catalyzed oxidative coupling of dibenzyl disulfide with amines ${ }^{a, b}$

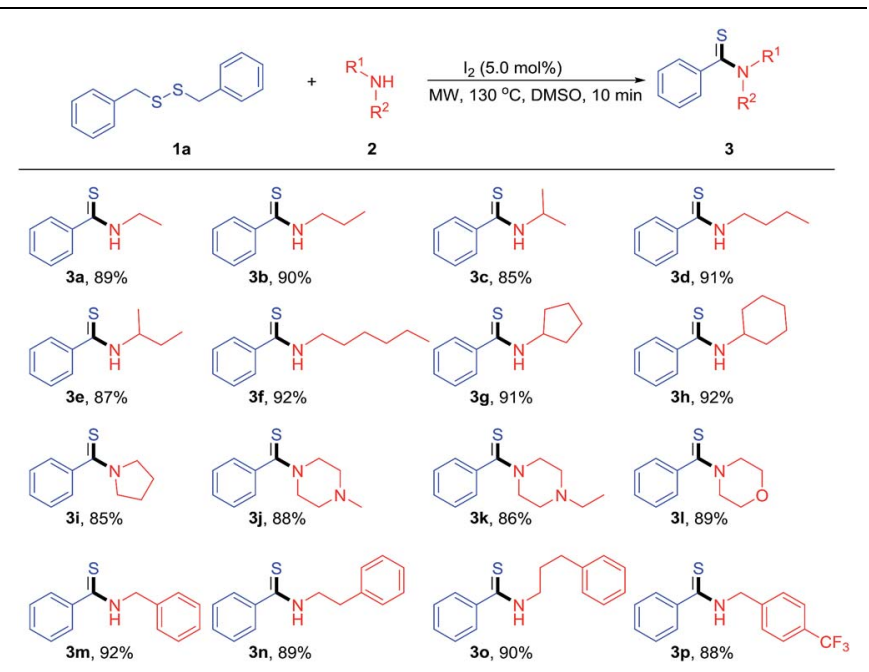

${ }^{a}$ Reaction conditions: dibenzyldisulfide $1 \mathrm{a}(0.5 \mathrm{mmol})$, amines 2 (1.0 $\mathrm{mmol}), \mathrm{I}_{2}(0.025 \mathrm{mmol})$, DMSO $(2.0 \mathrm{~mL}), 130{ }^{\circ} \mathrm{C}, 10 \mathrm{~min} .{ }^{b}$ Isolated yields based on dibenzyldisulfide $\mathbf{1 a}$.

both aliphatic amines and aralkyl amines could efficiently undergo oxidative coupling effectively, affording corresponding products in good to excellent yields. The length and the steric hindrance of the alkyl affected the reactions slightly, and gave corresponding products with an excellent yield of $85-92 \%$ (3a3h). The optimal conditions were also suitable for other $\mathrm{N}$ containing heterocyclic amines (such as pyrrolidine, morpholine, 1-methylpiperazine and 1-ethylpiperazine), and corresponding products were obtained in the yield of $85-89 \%$ (3i-3l). Good yield was also obtained, when dibenzyldisulfide (1a) was treated with benzylamine (2-phenylethan-1-amine or 3phenylpropan-1-amine) under the optimal conditions (3m-3p, 88-92\%), and the strong electron-withdrawing group $\left(\mathrm{CF}_{3}\right)$ presenting at the ring of the benzyl amine affected the thioamidation slightly, giving the desired product $3 \mathbf{p}$ in the yield of $88 \%$.

In subsequent studies, we examined the reaction of various amines with difurfuryl disulfide under the optimal conditions, and the results were summarized in Table 3. Analyzing Table 3, we can see that the thioamidation of difurfuryldisulfide with both alkylamines and heterocyclic amines gave desired products in moderate to good yields (3q-3w, 75-88\%). And the steric hindrance ( $n$-hexyl or cyclopentyl) of the aliphatic group affects the reaction slightly (3t and $3 \mathbf{u}, 80 \%$ and $83 \%$ ). To our delight, phenethyl amine was also prone to this thioamidation, for giving the desired product ( $3 \mathbf{w})$ in the yield of $87 \%$.

The thioamidation can also be carried out on a larger scale reaction, and the desired product (3a) were obtained in the yields of $87 \%$, when $5 \mathrm{mmol}$ of dibenzyldisulfide (1a) was treated with $10 \mathrm{mmol}$ of $N$-methylpiperazine (2a) under the standard conditions (Scheme 3a). To shed light on the mechanism of the reaction, dibenzyldisulfide (1a) was treated with $N$ methylpiperazine (2a) under standard conditions by using 2.0
Table 3 Microwave-assisted iodine-catalyzed oxidative coupling of difurfuryl disulfide with amines ${ }^{a, b}$

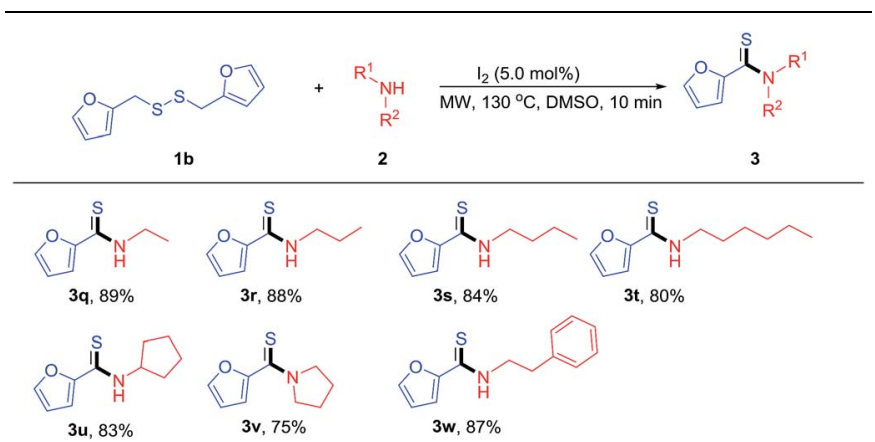

${ }^{a}$ Reaction conditions: difurfuryldisulfide (1b) ( $\left.0.5 \mathrm{mmol}\right)$, amines 2 (1.0 $\mathrm{mmol}), \mathrm{I}_{2}(0.025 \mathrm{mmol})$, DMSO $(2.0 \mathrm{~mL}), 130{ }^{\circ} \mathrm{C}, 10 \mathrm{~min} .{ }^{b}$ Isolated yields based on difurfuryldisulfide (1)

equiv. of TEMPO or BHT as radical scavengers (Scheme $3 \mathrm{~b}$ ), and desired product 3a was obtained in the yields of $86 \%$ and $80 \%$ respectively, suggesting that no single-electron transfer process was involved through the whole reaction. In addition, thioamides have been used as important intermediates for the construction of heterocycles and other compounds containing both nitrogen and sulfur in their backbones (Scheme 3c). ${ }^{18}$

On the basis of the above experimental results and previous works, ${ }^{16,19}$ a possible mechanism has been depicted in Scheme 4 . The first step of the thioamidation is the generation of the intermediate $\mathbf{A}$ by the reaction of dibenzyldisulfide (1a) with $\mathrm{I}_{2}$, with concomitant loss of $\mathrm{HI}$ and $\mathrm{BnS}^{-}$. Then intermediate $\mathbf{A}$ react with $N$-methylpiperazine (2a) to yield intermediate $\mathbf{B}$, which was converted to species $\mathbf{C}$ via coupling with $\mathrm{BnS}^{-}$in the presence of
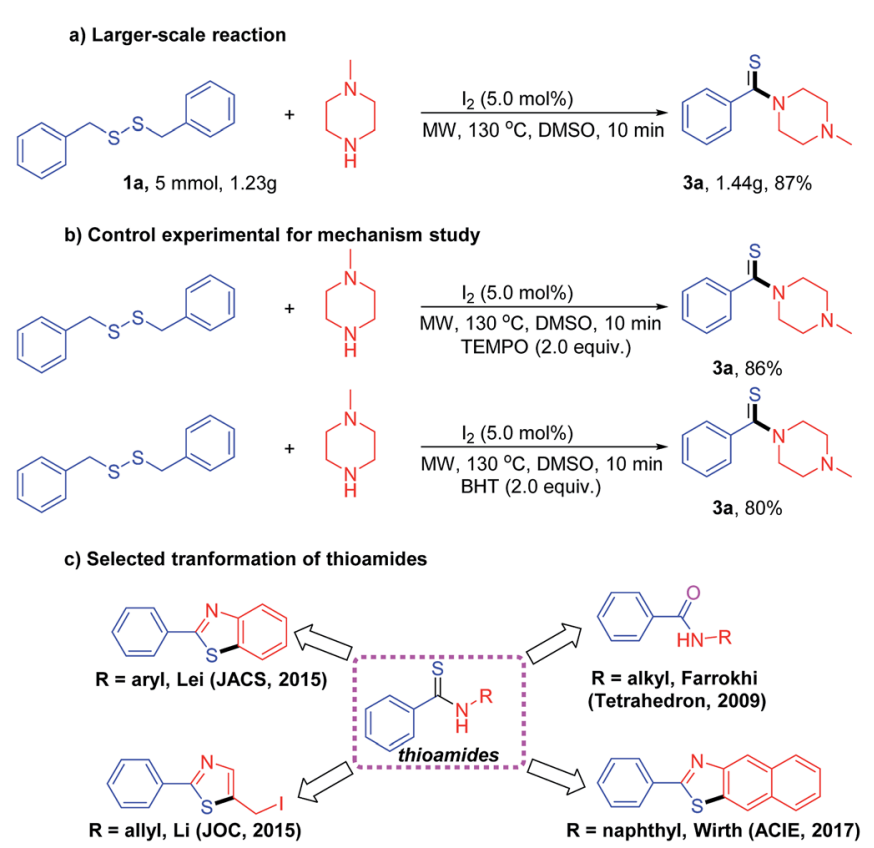

Scheme 3 (a) Larger-scale synthesis of 3a. (b) Control experimental for mechanism study. (c) Selected transformation of thioamides. 


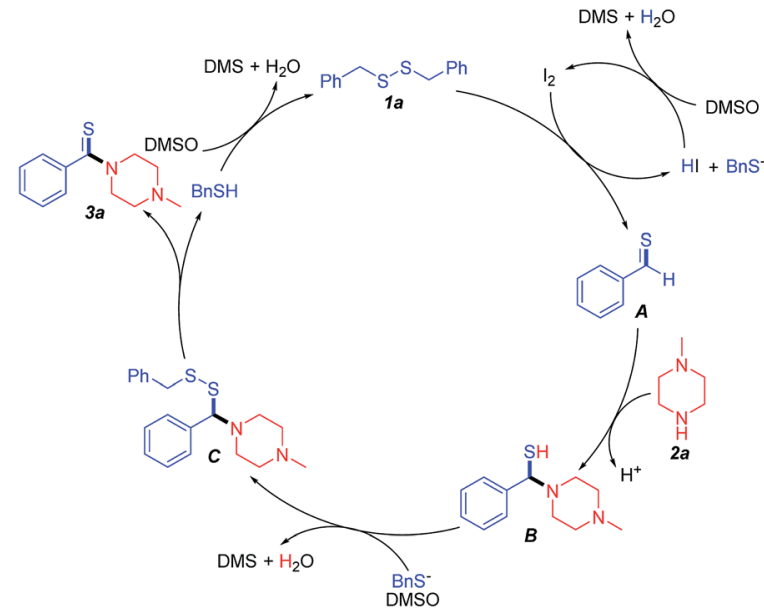

Scheme 4 Proposed mechanism of the thioamidation.

DMSO. Finally, species $\mathbf{C}$ decomposed to desired product (3a) and $\mathrm{BnSH}$, which was then converted to dibenzyldisulfide (1a) via oxidation reaction. During the whole reaction, the catalyst $\left(\mathrm{I}_{2}\right)$ was regenerated by the cycle of $\mathrm{HI}$ in the presence of DMSO, which catalyzed the thioamidation effectively.

\section{Conclusions}

In summary, we have developed a rapid and efficient protocol for the synthesis of thioamides via the microwave-assisted iodine-catalyzed oxidative coupling of dibenzyl(difurfuryl) disulfides with amines at $130{ }^{\circ} \mathrm{C}$ for 10 minutes. A broad range of amines were tolerated, and all the desired products could be obtained in good to excellent yields. Comparing with the previous methods, the present strategy has the advantages of high efficiency, simple operation, rapid reaction and less catalyst, providing a convenient way to thioamides, which are key intermediate for synthesis of other heterocycles compounds.

\section{Conflicts of interest}

There are no conflicts to declare.

\section{Acknowledgements}

We gratefully acknowledge the National Natural Science Foundation of China (21902014) and the Basic and Frontier Research Project of Chongqing (Cstc2018jcyjAX0051) for the funding support.

\section{Notes and references}

1 (a) T. S. Jagodziński, Chem. Rev., 2003, 103, 197; (b) T. Bretschneider, E.-M. Franken, U. Görgens, M. Fusslein, A. Hense and J. Kluth, US Pat., US9428487B2, 2016; (c) P. Jain, P. Verma, G. Xia and J.-Q. Yu, Nat. Chem., 2017, 9, 140; (d) X.-Y. Qian, S.-Q. Li, J. Song and H.-C. Xu, ACS Catal., 2017, 7, 2730; (e) R. W. Newberry, B. VanVeller and R. T. Raines, Chem. Commun., 2015, 51, 9624; (f)
N. Mahanta, D. M. Szantai-Kis, E. J. Petersson and D. A. Mitchell, ACS Chem. Biol., 2019, 14, 142.

2 (a) T. Lincke, S. Behnken, K. Ishida, M. Roth and C. Hertweck, Angew. Chem., Int. Ed., 2010, 49, 2011; (b) C. J. Schwalen, G. A. Hudson, B. Kille and D. A. Mitchell, J. Am. Chem. Soc., 2018, 140, 9494; (c) S. Coyne, C. Chizzali, M. N. A. Khalil, A. Litomska, K. Richter, L. Beerhues and C. Hertweck, Angew. Chem., Int. Ed., 2013, 52, 10564; (d) G. E. Kenney, L. M. K. Dassama, M.-E. Pandelia, A. S. Gizzi, R. J. Martinie, P. Gao, C. J. DeHart, L. F. Schachner, O. S. Skinner, S. Y. Ro, X. Zhu, M. Sadek, P. M. Thomas, S. C. Almo, J. M. Bollinger Jr, C. Krebs, N. L. Kelleher and A. C. Rosenzweig, Science, 2018, 359, 1411; (e) S. A. Abas, M. B. Hossain, D. van der Helm, F. J. Schmitz, M. Laney, R. Cabuslay and R. C. Schatzman, J. Org. Chem., 1996, 61, 2709.

3 S. Banala and R. D. Süssmuth, ChemBioChem, 2010, 11, 1335. 4 A. J. Van Der Vlies, U. Hasegawa and J. A. Hubbell, Mol. Pharmaceutics, 2012, 9, 2812.

5 M.-K. Chung, C. M. Hebling, J. W. Jorgenson, K. Severin, S. J. Lee and M. R. Gagné, J. Am. Chem. Soc., 2008, 130, 11819. 6 (a) A. Padwa, D. J. Austin, M. Ishida, C. L. Muller, S. S. Murphree and P. E. Yeske, J. Org. Chem., 1992, 57, 1161; (b) A. S. Hamman and B. E. Bayoumy, Collect. Czech. Chem. Commun., 1985, 50, 71; (c) C. R. Kelly, I. Gebhard and N. Wicnienski, J. Org. Chem., 1986, 51, 4590.

7 J. H. Miwa, L. Pallivathucal, S. Gowda and K. E. Lee, Org. Lett., 2002, 4, 4655.

8 P. W. Tan, A. M. Mak, M. B. Sullivan, D. J. Dixon and J. Seayad, Angew. Chem., Int. Ed., 2017, 56, 16550.

9 (a) J. M. Goldberg, S. Batjargal and E. J. Petersson, J. Am. Chem. Soc., 2010, 132, 14718; (b) W. Lin, X. Cao, Y. Ding, L. Yuan and L. Long, Chem. Commun., 2010, 46, 3529; (c) J. M. Goldberg, R. F. Wissner, A. M. Klein and E. J. Petersson, Chem. Commun., 2012, 48, 1550; (d) J. M. Goldberg, S. Batjargal, B. S. Chen and E. J. Petersson, J. Am. Chem. Soc., 2013, 135, 18651; (e) J. M. Goldberg, X. Chen, N. Meinhardt, D. C. Greenbaum and E. J. Petersson, J. Am. Chem. Soc., 2014, 136, 2086; $(f)$ C. Liu, T. Barrett, X. Chen, J. Ferrie and E. J. Petersson, ChemBioChem, 2019, 20, 2059.

10 (a) B. Kurpil, B. Kumru, T. Heil, M. Antonietti and A. Savateev, Green Chem., 2018, 20, 838; (b) Y. A. Tayade, A. D. Jangale and D. S. Dalal, ChemistrySelect, 2018, 3, 8895; (c) C. T. Brain, A. Hallett and S. Y. Ko, J. Org. Chem., 1997, 62, 3808; (d) J. Wei, Y. Li and X. Jiang, Org. Lett., 2016, 18, 340; (e) K. Kumar, D. Konar, S. Goyal, M. Gangar, M. Chouhan, R. K. Rawal and V. A. Nair, ChemistrySelect, 2016, 1, 3228.

11 (a) R. N. Hurd and G. DeLaMater, Chem. Rev., 1961, 61, 45; (b) R. Wegler, E. Kuhle and W. Schafer, Angew. Chem., Int. Ed., 1958, 70, 351; (c) H. R. Darabi, K. Aghapoor and M. Tajbakhsh, Tetrahedron Lett., 2004, 45, 4167.

12 (a) D. L. Priebbenow and C. Bolm, Chem. Soc. Rev., 2013, 42, 7870; (b) K. Aghapoor, H. R. Darabi and K. Tabar-Heydar, Phosphorus, Sulfur Silicon Relat. Elem., 2002, 177, 1183; (c) K. Okamoto, T. Yamamoto and T. Kanbara, Synlett, 2007, 
2687; (d) T. Cuntreddi, R. Vanjari and K. N. Singh, Tetrahedron, 2014, 70, 3887.

13 (a) D. C. Smith, S. W. Lee and P. L. Fuchs, J. Org. Chem., 1994, 59, 348; (b) F. M. Moghaddam and M. Ghaffarzadeh, Synth. Commun., 2001, 31, 317; (c) Z. Kaleta, G. Tárkányi, Á. Gömöry, F. Kálmán, T. Nagy and T. Soós, Org. Lett., 2006, 8, 1093; (d) Z. Kaleta, B. T. Makowski, T. Soós and R. Dembinski, Org. Lett., 2006, 8, 1625.

14 T. B. Nguyen, L. P. Anh Nguyen and T. T. T. Nguyen, Adv. Synth. Catal., 2019, 361, 1787.

15 (a) N. D. Koduri, H. Scott, B. Hileman, J. D. Cox, M. Coffin, L. Glicksberg and S. R. Hussaini, Org. Lett., 2012, 142, 440; (b) S. P. Pathare, P. S. Chaudhari and K. G. Akamanchi, Appl. Catal., A, 2012, 425, 125; (c) Z. Zhou, J.-T. Yu, Y. Zhou, Y. Jiang and J. Cheng, Org. Chem. Front., 2017, 4, 413; (d) M. F. Aly and R. Grigg, Tetrahedron, 1988, 44, 7271; (e) X. Li, Q. Pan, R. Hu, X. Wang, Z. Yang and S. Han, Asian J. Org. Chem., 2016, 5, 1353; (f) N. Borthakur and A. Goswami, Tetrahedron Lett., 1995, 36, 6745; $(g)$ S. Kumar, R. Vanjari, T. Guntreddi and K. N. Singh, Tetrahedron, 2016, 72, 2012.
16 S. Chen, Y. Li, J. Chen, X. Xu, L. Su, Z. Tang, C.-T. Au and R. Qiu, Synlett, 2016, 27, 2339.

17 (a) C. Bordoni, C. M. Cima, E. Azzali, G. Costantino and A. Brancale, RSC Adv., 2019, 9, 20113; (b) A. M. Rodríguez, P. Prieto, D. R. Martín and J. I. García, ChemistryOpen, 2015, 4, 308; (c) R. Rahaman, N. Devi, K. Sarma and P. Barman, RSC Adv., 2016, 6, 10873; (d) S. K. Bhatia, V. Samdhian and B. Kaur, J. Heterocycl. Chem., 2018, 55, 935; (e) A. Kokel, C. Schäfer and B. Török, Green Chem., 2017, 19, 3729.

18 (a) K. Bahrami, M. M. Khodaei and A. Farrokhi, Tetrahedron, 2009, 65, 7658; (b) G.-Q. Liu, C.-H. Yang and Y.-M. Li, J. Org. Chem., 2015, 80, 11339; (c) G. Zhang, C. Liu, H. Yi, Q. Meng, C. Biao, H. Chen, J.-X. Jian, L.-A. Wu and A. Lei, J. Am. Chem. Soc., 2015, 137, 9273; (d) A. A. Folgueiras-Amador, K. Philipps, S. Guilbaud, J. Poelakker and T. Wirth, Angew. Chem., Int. Ed., 2017, 56, 15446.

19 (a) M. Wang, J.-C. Xiang, Y. Cheng, Y.-D. Wu and A.-X. Wu, Org. Lett., 2016, 18, 524; (b) X. Wang, M. Ji, S. Lim and H.-Y. Jang, J. Org. Chem., 2014, 79, 7256. 